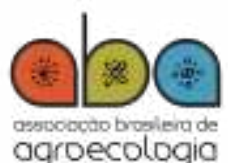

ISSN: 1980-9735

DOI: 10.33240/rba.v14i2.22951

Vol. 14 | №. 2 Esp.| p. $35-50 \mid 2019$

\title{
CONSTRUÇÃO DA POLÍTICA DE AGROECOLOGIA E PRODUÇÃO ORGÂNICA NO DISTRITO FEDERAL
}

\author{
Construction of agroecology and organic production policy in the \\ Federal District (Brazil)
}

Eric Pierre Sabourin ${ }^{1}$, Luiz Raimundo Tadeu Da Silva ${ }^{2}$ e Mario Lucio de Avila ${ }^{2}$

\footnotetext{
1 Pesquisador do CIRAD Umr Art dev, Université de Montpellier e professor visitante na Universidade de Brasilia, no Centro de Desenvolvimento Sustentável e no programa MADER da Faculdade de Planaltina. E-mail: eric.sabourin@cirad.fr

${ }^{2}$ Programa MADER Meio ambiente e Desenvolvimento Rural pela Universidade de Brasília Faculdade de Planaltina (UnB/FUP).

E-mail: unbavila@gmail.com; luizsilva@bce.unb.br

Recebido em: 15/04/2019

Aceito para publicação em: 25/05/2019

Correspondência para:

eric.sabourin@cirad.fr
}

\section{RESUMO}

O objetivo desse artigo é analisar o processo de construção de instrumentos a favor da agroecologia e da produção orgânica no Distrito Federal do Brasil, em particular, a criação de uma política distrital. 0 estudo associa a sociologia da ação pública e a análise de redes de ação pública. A metodologia combina a análise de documentos e arquivos com entrevistas de 17 atores chaves desse processo. Os resultados mostram como três grupos de interesse, originados por uma elite de poucos militantes pioneiros organizados desde os anos 1980, têm se constituído em uma rede de ação pública, que promoveu várias iniciativas, eventos, instituições e instrumentos, sendo a mais recente a criação da Política Distrital de Agroecologia e Produção Orgânica - PDAPO-DF, em 2017.

Palavras-chave: Agroecologia. Produção Orgânica. Rede De Política Pública. Distrito Federal.

\section{ABSTRACT}

The objective of this article is to analyze the process of building instruments in favor of agroecology and organic production in the Federal District of Brazil, particularly the creation of a district policy. The study associates the sociology of public action and policy networks analysis. The methodology combines the analysis of documents and interviews of 17 key actors of this process. The results show how three interest groups, originated by an elite of few pioneer militants organized since the 1980s, have been constituted in a public action network that promoted several initiatives, events, institutions and instruments, the most recent being the creation of the District Policy for Agroecology and Organic Production - PDAPO-DF, in 2017.

Keywords: Agroecology. Organic Agriculture. Public Policy Network. Brazil. 
Introdução

Desde 2013, o Brasil conta com uma Política Nacional de Agroecologia e Produção Orgânica (PNAPO), que reúne mais de 120 ações de dez ministérios sob a coordenação da Secretaria da Presidência da República. As ações foram conduzidas a nível federal, de acordo com o I Plano Nacional de Agroecologia e Produção Orgânica, o PLANAPO 1, para o período de 2012 a 2015 (SCHMITT et al., 2017). Alguns estados federados passaram a adotar e construir esse tipo de política em paralelo ou depois da promulgação da PNAPO, em diálogo com a sociedade civil, mediante câmaras ou comissões estaduais de agroecologia e produção orgânica (GUÉNEAU et al., 2019, nesse número). O artigo apresenta uma análise da recém-criada Política Distrital de Agroecologia e Produção Orgânica do Distrito Federal (PDAPO-DF), promulgada em janeiro de 2017. Essa política, sendo muito recente, não pode ainda ser avaliada. No entanto, foi precedida por uma série de iniciativas, instrumentos, programas que contribuíram para a sua formulação (TADEU DA SILVA, 2019). É, mais especificamente, o exame dessa trajetória, dos seus atores e processos que caracteriza o presente estudo. O referencial teórico associa a análise de políticas públicas e a sociologia da ação pública (LAGROYE et al, 2006; LASCOUMES e LE GALES, 2012), em particular, a análise das redes de ação pública (MARSH e RHODES, 1992; RHODES, 2008). Segundo Leslie Pal (1992) uma política pública constitui "uma série de ações ou inações que autoridades públicas escolhem adotar para regular ou responder a um problema ou um conjunto de problemas interligados" (PAL, 1992, p. 2). Para Simeon, a política pública é "o que os governos fazem e porque o fazem" (SIMEON, 1976, p 548); mas, segundo Dye, é, também, o que os governos "escolhem não fazer" (DYE, 1984, p 1).

A abordagem da PDAPO e dos dispositivos e instrumentos que a antecederam baseia-se no referencial conceitual e metodológico do estudo da ação pública. Lagroye et al. (2002, p. 501) definem a ação pública como o "conjunto de efeitos, não necessariamente previsíveis e coerentes, resultantes de interações entre instituições interdependentes, entre os agentes dessas instituições e uma quantidade de atores sociais interessados pelas decisões políticas".

Lascoumes e Le Gales (2012) propõem analisar a ação pública a partir das relações entre cinco elementos: os atores, as representações, as instituições, os processos e os resultados.

Os atores podem ser individuais ou coletivos, são dotados de recursos, têm certa autonomia, estratégias e são capazes de fazer escolhas, são mais ou menos guiados por seus interesses materiais e/ou simbólicos. As representações são os quadros cognitivos e normativos que dão sentido às ações, as condicionam e as refletem. As instituições são as normas, regras, rotinas, procedimentos que governam as interações. Os processos são as formas de interação e sua recomposição no tempo (...). Os resultados, (outputs) são as consequências, os efeitos da ação pública (LASCOUMES e LE GALES, 2012, p. 4546).

A noção de rede de ação pública vem completar esse enfoque, dialogando com ele em torno das relações entre os atores que promovem as políticas. Segundo Rhodes (2008) "As redes de políticas públicas são conjuntos de ligações institucionais formais e informais entre agentes governamentais e outros atores estruturados em torno de crenças e interesses compartilhados, negociados de forma permanente, na formulação e implementação de políticas públicas" (RHODES, 2008, p. 426). Foram também definidas como

O resultado de cooperação não hierárquica mais ou menos estável entre organizações que se conhecem e se reconhecem, negociam, trocam recursos e podem compartilhar normas e interesses. Essas redes desempenham um papel decisivo na definição da agenda, da decisão e da implementação da ação pública (LE GALES e THATCHER, 1995, p. 15). 
Nossa principal hipótese é que os diversos instrumentos e programas a favor da agroecologia implementados no DF e, finalmente, a PDAPO-DF, foram promovidos por uma coalizão da agroecologia e produção orgânica que reúne diversos grupos de interesse. Identificamos três principais: i) os produtores e movimentos da agroecologia; ii) os produtores e organizações da produção de orgânicos; e iii) o setor público. Uma segunda hipótese considera que esses grupos de interesse, embora defendam em primeiro lugar suas próprias causas, conseguiram interagir ou se unir, constituindo uma rede de ação pública a favor da agroecologia e da produção orgânica, mais ou menos estruturada e mais ou menos forte, segundo os seus momentos na sua trajetória desde os anos 1980 até hoje (SILVA, 2019).

A metodologia combina a análise de documentos e arquivos com entrevistas de 17 atoreschaves, gestores, políticos, técnicos, acadêmicos e representantes das organizações de agricultores. Foi aplicado um arcabouço analítico comum a outros estudos sobre as políticas estaduais de agroecologia e produção orgânica no Brasil realizados no marco dos trabalhos da Rede "Políticas Públicas e Desenvolvimento Rural na América Latina" (SABOURIN et al., 2018; GUENEAU et al., 2019). O artigo está dividido em quatro partes. A primeira apresenta os atores e instituições- chaves no processo de construção da PDAPO-DF; a segunda introduz as suas representações e a terceira os processos e coalizões; finalmente, a quarta parte trata da governança e dos instrumentos.

Os atores-chaves na promoção da agroecologia e da produção orgânica no DF

\section{Os pioneiros: um grupo de elite programática}

A maioria das ações a favor da agroecologia e da produção orgânica no DF passa por um pequeno grupo de militantes pioneiros. Este grupo inclui agrônomos de Brasília que, desde os anos 1980-1990, promoveram iniciativas individuais e integraram o movimento social da agricultura alternativa no DF. Este grupo de pioneiros recém-formados e militantes da agricultura alternativa foi determinante para a promoção da agricultura ecológica e orgânica nos anos seguintes. Eles se tornaram líderes de movimentos sociais, por exemplo, na Federação de Agrônomos do Brasil, e em 1989 criaram, em Brasília, a Associação de Agricultura Ecológica (AGE). Desde as décadas de 1980 a 1990, passaram a ocupar espaços públicos e privados favoráveis à agricultura ecológica. Por exemplo, dentre os entrevistados, uma foi produtora e é hoje Presidente da AGE; um foi técnico e logo responsável da produção orgânica e agroecológica na Empresa de Assistência Técnica e Extensão Rural do DF (EMATERDF); outro foi responsável pela produção orgânica e logo agroecológica no Ministério de Agricultura Pecuária e Abastecimento (MAPA), outro se tornou dono da maior empresa de orgânicos do DF. Este último foi deputado distrital, Secretário de Ciência e Tecnologia do DF e até Presidente da EMATER e promoveu a criação da AGE e do Sindicato dos Produtores de Orgânicos do DF (Sindiorgânicos).

Outros membros desse grupo ocuparam cargos na área de ensino e pesquisa e extensão como professores e pesquisadores na Universidade de Brasília (UnB), no Instituto Federal de Brasília (IFB), na Empresa Brasileira de Pesquisa Agropecuária (EMBRAPA) e na EMATER-DF. Podemos reconhecer nesses pioneiros um grupo de "elites programáticas" de vários instrumentos e dispositivos de agroecologia no DF e até da gênese da atual PDAPO-DF. De acordo com Genieys (2007), as elites programáticas se caracterizam por trajetórias setoriais na alta administração do Estado, onde combinam habilmente uma aprendizagem profissional específica que coincide com o contorno atual de políticas públicas. Pudemos verificar isso com as carreiras de quatro desses pioneiros na esfera federal (MAPA, EMBRAPA, UnB) e distrital (Deputado, Direção da EMATER, da Secretaria de Ciência e Tecnologia). Eles desenvolveram estratégias de carreira ancoradas em torno de um tema privilegiado e setor público específico: aqui a agroecologia e a produção orgânica. O seu poder se manifesta por uma alta concentração de capacidade em torno de um programa de ação pública singular resultando na formação de um sentido forte de identidade do grupo. 
Uma trajetória de "transição agroecológica institucional"

A noção de Agroecologia emerge como novo conceito da agricultura alternativa nos anos 2000. Mas, segundo os técnicos da EMATER-DF, foi difícil mudar o rumo das instituições de ciência e tecnologia, bem como da Secretaria de Agricultura. Nos anos 1990 existia, segundo o seu Presidente atual, "uma atividade dispersa da EMATER-DF a favor da agricultura mais comercial". Em 1999, a Secretaria de Estado da Agricultura, Abastecimento e Desenvolvimento Rural do Distrito Federal (SEAGRI-DF) financiou um incentivo à produção orgânica no âmbito do ProRural, um programa de apoio às cadeias produtivas. Na continuidade das ações da AGE e da EMATER-DF, a Comissão da Produção Orgânica (CPORG) do DF é criada em 1999 e o Sindiorgânicos, em 2002.

Segundo a então coordenadora de agroecologia, dentro da EMATER-DF houve um processo de "transição agroecológica institucional" a partir do grupo pioneiro da agricultura alternativa. Também foi determinante a força dos movimentos sociais para trazer a agroecologia aos assentamentos de reforma agrária do DF. O Ministério do Desenvolvimento Agrário (MDA) financiou a assistência técnica agroecológica (ATER Agroecológica) a partir da sigla PNATER e a comercialização com preços diferenciados para produtos orgânicos, mediante o Programa de Aquisição de Alimentos da agricultura familiar (PAA). Em 2005, um Arranjo Produtivo Local (APL) centrado na produção orgânica foi lançado pelo governo do DF com o objetivo de reforçar os laços e intercâmbios de conhecimentos entre os atores. Hoje a EMATER-DF conta com extensionistas capacitados em agroecologia e produção orgânica.

A trajetória das ações, eventos e instrumentos a favor da agroecologia e produção orgânica no DF é marcada por três fases bem distintas:

- 1980 a 1998: da agricultura alternativa à agricultura ecológica, marcada pela AGE;

- 1999 a 2008: a consolidação da produção orgânica em 2008, após a criação da CPORG e do Sindiorâgnicos, com a instalação do Mercado Orgânico na Central de Abastecimento do Distrito Federal (CEASA-DF);

- de 2008 até hoje, com a emergência de instrumentos para a agroecologia, o florescimento das feiras agroecológicas, a criação da PNAPO em 2012, da PDAPO-DF em 2017 e a realização do Congresso Brasileiro de Agroecologia em Brasília (CBA).

\section{Representações: as concepções da agroecologia na PDAPO}

O texto da lei que rege a PDAPO-DF oferece várias definições dos conceitos utilizados. Elas retomam os termos utilizados no texto da PNAPO. No entanto, não aparece uma diferenciação clara entre a agroecologia (termo genérico, mas amplo para uma "agricultura ecológica ampliada a justiça social") e a produção orgânica qualificada como "um dos sistemas de produção para chegar à agroecologia, ao lado dos sistemas de produção de base agroecológica" (DISTRITO FEDERAL, 2017, p. 2). É mantida a nuance entre as duas concepções, recomendando:

[...] para os sistemas de produção orgânica utilizar "sempre que possível, métodos culturais, biológicos e mecânicos, em contraposição ao uso de materiais sintéticos; a eliminação do uso de organismos geneticamente modificados e radiações ionizantes, em qualquer fase do processo de produção, processamento, armazenamento, distribuição e comercialização (DISTRITO FEDERAL, 2017, p. 2).

Segundo a então coordenadora do programa de agroecologia e produção orgânica da EMATER-DF, foi preciso sensibilizar os produtores para alternativa de transição para agroecologia por meio das práticas concretas, não do discurso e da ideologia. Para ela, "a produção orgânica é diferente da agroecologia; é mais uma substituição de insumos que de práticas e de concepção, mas as duas têm a ligação comum de responder a uma demanda crescente do mercado dos consumidores do DF" (Entrevista, em 29/06/2018). 
Ela considera que "agroecologia permite responder a uma diversidade de demandas e de situação, mas sem pretensão a gerar automaticamente uma conversão" (Entrevista, em 29/06/2018). Os membros da Articulação Brasiliense de Agroecologia (ABRAA) adotam a definição da ecologia política e da ecologia "como ciência" (Altieri, 1995). Para um fundador da AGE que foi responsável pela primeira Coordenação da produção Orgânica no MAPA:

quando a gente escreveu a Lei da agricultura orgânica, e depois quando a gente construiu o regulamento, o decreto, em 2007, usamos como princípios da agricultura orgânica os princípios da agroecologia. Então se você pega o começo da lei, o que se considera e quais são os objetivos da agricultura orgânica são os princípios da agroecologia (Entrevista).

Para a presidente da AGE, no DF, agroecologia e produção orgânica são irmãs gêmeas, "filhas da agricultura alternativa da década de 1980, pois gravitam em torno do mesmo eixo composto pelo tripé: não uso de fertilizante químico, não uso de agrotóxico e preservação do ambiente". Além disso, a agroecologia é considerada pela associação um movimento contra- hegemônico, uma forma de produzir alimentos, recompondo e mantendo a paisagem natural do terreno. Significa produzir alimentos paralelamente a um trabalho de recomposição ou manutenção do ecossistema em função da paisagem natural.

Por fim, os membros dessa coalizão entendem que, na produção orgânica, pode-se modificar toda a paisagem natural e plantar diversos hectares de um mesmo produto. Tanto é que a certificação é direcionada para o produto e não para a propriedade. Então pode ter um produto orgânico que não é oriundo de uma produção agroecológica. Porém, segundo a perspectiva da agricultura alternativa, agroecologia e produção orgânica são formas de atuação diferentes, mas não antagônicas. Gliessman (2014) reconhece que a produção orgânica é um dos caminhos da transição agroecológica. O mesmo ocorre com lideranças entrevistadas "o meu produto é orgânico e sua produção é agroecológica, por isso minha órbita dentro do sistema é mais que produzir alimentos saudáveis.... Vou dizer que a minha produção é agroecológica, e a certificação garante que o produto é orgânico" (Entrevista dirigente da AGE).

Para vários membros da ABRAA, essa preocupação não é nova e deve ser recolocada no espectro das forças e das etapas, numa trajetória para fortalecer uma coalizão, a fim de promover a agroecologia. Reconhecer a produção orgânica e associar o movimento social da agricultura biológica ou orgânica ao movimento da agroecologia era essencial é indispensável, conforme expressa uma liderança entrevistada: "porque a gente optou por agricultura orgânica nos anos 90? Foi um consenso, tínhamos a Federação Internacional dos Movimentos de Agricultura Orgânica (IFOAM) que tinha essa visão, tínhamos os EUA com a sua Lei dos orgânicos, entendíamos, naquele momento, que a sociedade estava mais preparada para uniformizar o sentido em termos de agricultura orgânica".

No entanto, segundo animadores do Núcleo de Estudos de Agroecologia (NEA) da UnB, essa proximidade "pragmática" entre agroecologia e produção orgânica termina mantendo, nas instituições e nas políticas públicas do DF, uma visão reduzida da agroecologia, uma versão mais tecnológica quando não tecnocrática.

Os processos: grupos de interesse e coalizões políticas

Como vimos, o grupo de interesse da produção orgânica e aquele da agroecologia têm a mesma origem, no grupo de pioneiros dos anos 1980. No entanto, segundo os momentos e os temas em pauta, estes grupos vão defender propostas comuns ou propostas próprias a interesses específicos. O grupo dos servidores do DF e do governo federal compartilha ações, apoia de forma alternada os dois grupos de interesse de produtores agroecológicos e de empresários orgânicos. Esses três grupos de 
interesse formam uma coalizão que promoveu políticas públicas de agroecologia e produção orgânica, e compete por recursos públicos com a coalizão da agricultura familiar produtiva (público do Pronaf) e com a coalizão do agronegócio (SABATIER e JENKINS, 1993). Não analisaremos aqui as relações entre essas três coalizões da agricultura no DF. Apenas vamos examinar os atores, componentes, propostas e ações defendidas por cada um desses grupos de interesse que configuram a coalizão da agroecologia e da produção orgânica (ver Tabela 1). O importante é notar que, no caso específico do DF, esses três grupos de interesses foram capazes de se unir, apesar das diferenças, para avançar em uma proposta de apoio público a uma agricultura mais ecológica e a produtos orgânicos certificados.

\section{O grupo de interesse da produção orgânica}

O grupo de interesse da produção orgânica se fortalece quando é necessário um processo de certificação para distinguir produtos realmente agroecológicos e orgânicos de outros produtos nas feiras e outros pontos de venda de Brasília. Ele foi determinante para a criação da CPORG e para a certificação dos produtos, além disso é conduzido por produtores cuja manutenção depende da venda da sua produção, tendo sido progressivamente liderado por produtores maiores (médios e empresários) como a Malunga, o sítio Corujinha, a AGE.

Não tinha nada que desse mais raiva para gente quando começamos com a nossa feirinha da Asa Norte, na Messiânica, que uns caras que montaram uma feira do outro lado da rua, com a faixa de produto orgânico, mas compravam na CEASA e por isso tinham muito mais itens que nós. Assim a gente não podia fazer nada, porque não tinha legislação que punisse o que eles estavam fazendo. Qualquer um podia se denominar produtor orgânico porque não tinha nada que impedisse. Então, para mim era muito claro que ter uma legislação era parte do processo (Entrevista dirigente da AGE).

Segundo os produtores pioneiros entrevistados, eles "conseguiram, no primeiro momento, sobreviver e não falir porque agregaram valor econômico ao produto e tiraram alguns atravessadores". No ano de 1995, organizaram o 10 Seminário de Agricultura Alternativa do Distrito Federal. Em 1999 criaram a CPORG do DF e, em 2002, tiveram acesso à certificação por meio do Sindiorgânicos. Para os produtores isso foi essencial: "Agora não precisa mais o produtor falar com o consumidor de que seus produtos são saudáveis e preservam o meio ambiente. Tem uma instância que certifica isso".

Depois da criação do Sindiorgânicos, com o apoio da Fundação Mokiti Okada, do Serviço e Apoio às Micro e Pequenas Empresas do DF (SEBRAE-DF), da ECOCERT Brasil, os esforços dos produtores orgânicos grandes e médios do DF (Malunga, AGE e outros) se concentraram na obtenção de um espaço de comercialização na CEASA-DF (ver tabela 1). Para isso, teceram alianças mais amplas para obter apoio do MDA, da SEAGRI-DF e até da Confederação Nacional dos Trabalhadores na Agricultura (CONTAG), que apoiava um projeto de comercialização da Região Integrada de Desenvolvimento do Distrito Federal e Entorno (RIDE-DF) na CEASA, justificando o envolvimento de 80 agricultores familiares do DF. Para isso, foi criada a Associação do Mercado Orgânico do DF, dirigida por um núcleo de pequenos empresários. Em 2004, um financiamento do MDA foi obtido para a construção do mercado através do Território da Cidadania Águas Emendadas. No entanto, o projeto teve que esperar até 2008 para ser concretizado com um co-financiamento da SEAGRI-DF e um complemento da Secretaria de Ciência e Tecnologia do DF.

Os integrantes desse grupo de interesse, em particular suas lideranças, têm uma visão empresarial e comercial da produção orgânica e agroecológica. Essa estratégia convém para uma demanda urbana como a de Brasília, para venda em supermercados, restaurantes, lojas orgânicas e feiras. No entanto, para poder escoar quantidades importantes, esse grupo precisava, também, de um espaço comercial estrategicamente situado na CEASA-DF. Depois de experiências de venda improvisada no estacionamento da CEASA, mas sem nenhuma infraestrutura, o grupo se consolidou e, ao mesmo tempo, de certo modo se fechou com o projeto do Mercado Orgânico do DF. Nessa empreitada, o grupo contou com o apoio de instituições que compartilham essa visão empresarial, como o SEBRAE, o Sindicato dos Orgânicos e a Ecocert Brasil. A aliança provisória com a Agência Regional de 
Comercialização para Agricultura familiar da RIDE-DF (ARCO), criada por iniciativa da CONTAG, foi mais estratégica para obter o financiamento do Mercado Orgânico por meio MDA, no marco do Território Águas Emendadas (LANDEL, 2009).

A trajetória do projeto do Mercado Orgânico mostra a habilidade e a atuação estratégica de verdadeiros "empreendedores de política pública". Para Kingdon (1984) são pessoas dispostas a investir seus recursos - tempo, energia, reputação, dinheiro - para promover uma posição em troca de um ganho futuro, antecipado na forma de benefícios materiais, propositais ou solidários. Massardier define assim esse perfil de gestor de políticas públicas:

Os empreendedores estão dispostos a mobilizar seus próprios recursos - tempo, energia, reputação, dinheiro - para investir em uma posição na expectativa de um retorno sob a forma de benefícios. 'Eles têm três qualidades' i) a capacidade de ouvir os outros e de falar em seu nome, ocupando uma posição de decisão; ii) a capacidade de ser reconhecidos pelo seu capital social, por seus recursos em termos de rede e competências de negociador; ii) pela sua persistência e tenacidade na ação. Estes empreendedores de políticas públicas procuram seus próprios benefícios na promoção de uma concepção de política pública que tentam impor na agenda política (MASSARDIER, 2008, p. 36).

Landel (2009) mostra a evolução das alianças construídas para obter o apoio público do Mercado Orgânico. O projeto inicial contava apenas com pequenos empresários. Em 2005, para obter o financiamento do MDA, justifica-se o ingresso de 80 agricultores familiares. Em 2009, a associação de produtores é substituída por uma cooperativa que requer um mínimo de 20 sócios, assim foram mantidos apenas 2 ou 3 agricultores familiares a título simbólico.

\section{O grupo de interesse da agroecologia}

Essa coalizão reúne os intelectuais e técnicos na ABRAA e algumas lideranças da produção familiar agroecológica do DF, basicamente de assentamentos da reforma agrária que seguiram cursos promovidos pelo IFB, a UnB, a EMATER-DF ou a EMBRAPA Hortaliças. A coalizão da agroecologia se consolidou em torno da expressão local e, principalmente, dos membros do movimento social brasileiro da agroecologia, a Articulação Nacional da Agroecologia (ANA) e a Associação Brasileira de Agroecologia $(A B A)$. Segundo um coordenador regional da $A B A$, "A terminologia agricultura orgânica já vinha se consolidando e a colocação do Altieri é que a agroecologia era a base científica. Isto foi fundamental para responder as críticas e brigas na Federação de Associações de agrônomos onde nos diziam anticiência e que nós estávamos indo contra a ciência moderna da agricultura que embasava a revolução verde. E que nós éramos contra esses avanços tecnológicos da revolução, e então nós estávamos indo contra a ciência".

Esta coalizão passou a demonstrar maior expressão a partir de 2008, com a organização bianual do seminário de agroecologia do DF e a realização, em 2017, do X Congresso da ABA, em conjunto com o VI Congresso da Sociedade Latino-americana de Agroecologia. A criação da ABRAA aconteceu no processo de organização dos seminários de agroecologia do DF, que integraram o sistema de organização do Congresso Brasileiro de Agroecologia (CBA) com encontros regionais a cada dois anos. Esta é composta por EMATER-DF, EMBRAPA Cerrado, EMBRAPA Cenargen, EMBRAPA Hortaliças, IFB e UnB.

Não sendo formalizada juridicamente, a ABRAA se caracteriza como uma rede de ação pública, visando debates e difusão do conhecimento agroecológico no DF e região, e a implementação de políticas públicas a favor da agroecologia. Dois tipos de atores integram esta articulação: os indivíduos (pessoas) militantes da Agroecologia e Produção Orgânica e as instituições públicas em que esses indivíduos atuam (ver tabela 1). Seu objetivo principal é organizar os Seminários de Agroecologia e Produção Orgânica do Distrito Federal. Os seminários não eram elementos de implementação das políticas públicas de desenvolvimento rural. Tal articulação de pessoas, assim como os seminários, influenciaram as instituições públicas na mobilização em favor da agroecologia. Com isso, em 2012 
nasceu a ABRAA, cujos membros incluíam, na sua grande maioria, servidores públicos e estudantes universitários, professores, pesquisadores da EMBRAPA, técnicos da EMATER e de ONGs.

Os seminários são um dos dispositivos que impulsionam o desenvolvimento da agroecologia, tanto nas práticas agrícolas quanto na co-construção de conhecimentos e saberes. Seus resultados reverberam politicamente na ação pública do DF. Portanto, a ABRAA constituiu uma importante novidade no campo da agroecologia no DF. Ela se articula em três níveis: i) no nível pessoal/individual, para ganhar força em suas instituições; ii) no nível institucional; e iii) no nível de ação pública distrital pela união dessas instituições a favor da agroecologia.

De fato, os seminários do DF surgiram tanto das ações individuais quanto institucionais, para apresentação dos resultados dos projetos de agroecologia e produção orgânica em curso e das reflexões do movimento. Nesses seminários acontece, também, a retroalimentação de ideias, reconhecimentos de parceiros e sensibilização de gestores de órgãos governamentais. Portanto, os seminários são a estrutura de sentido (o objetivo maior) da ABRAA. Através deles se percebe a vontade de construção de uma rede de ação pública dedicada à defesa e ao aprimoramento da PDAPO-DF, bem como ao apoio à gestão local do conhecimento agroecológico. A coalizão atuou na difusão do conhecimento agroecológico e a ABRAA também conseguiu apoio para realizar os eventos, construir agendas, dialogar com deputados e gestores de políticas públicas. A figura 1 ilustra a trajetória dessa coalizão de ação pública do DF. Os principais resultados da coalizão da agroecologia do DF que perpassam outros espaços, além do conhecimento, foram capitaneados pela ABRAA. Observou-se, de forma geral, um aumento da circulação de ideias e conhecimentos de temas sobre a agroecologia.

Figura 1. Linha do tempo das ações da ABRAA e da coalizão da agroecologia no DF

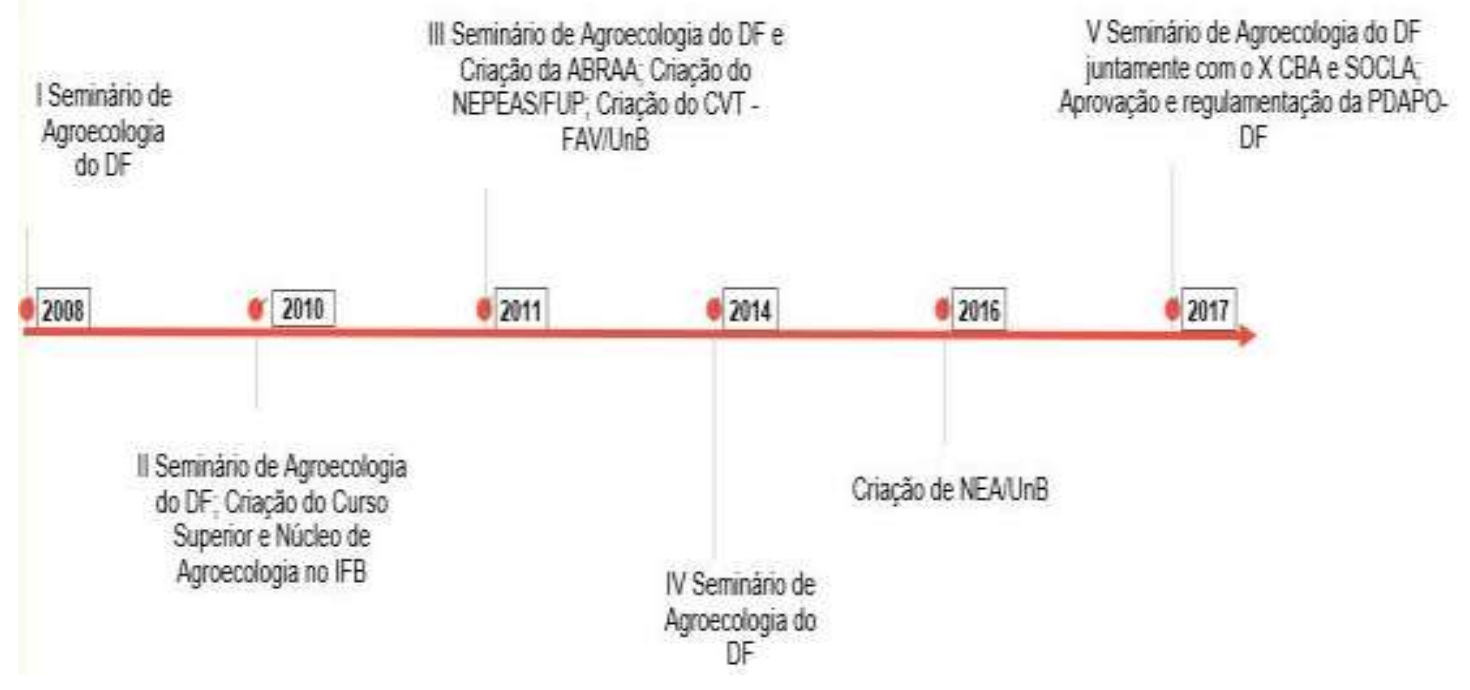

Finalmente, a proposta, a tramitação e a aprovação da PDAPO-DF foram as últimas conquistas dessa rede que colocou seus atores-chaves na Câmara de Agroecologia e Produção Orgânica do DF (CAO). No entanto, os grupos dos orgânicos e da agroecologia tiveram seus enfrentamentos e diferenças internas, inclusive dentro da AGE, quando as preocupações eram contraditórias ou exclusivamente voltadas para a comercialização. Isso levou à saída de vários membros fundadores da AGE, segundo um deles: "Um dos motivos por que eu saí da AGE e outros dos fundadores foi porque ela acabou se transformando numa associação para viabilizar feiras. Então toda reunião da AGE era para discutir os pontos de vendas, quem vai produzir. Não conseguíamos que a AGE fosse o que tinha sido proposto na sua criação, ser um espaço de discussão de como a agricultura alternativa poderia crescer e encapar ações".

De fato, na época das tensões na AGE, quem se definia apenas como produtor agroecológico e não dependia apenas das vendas para viver (porque produzia, também, para o autoconsumo), como os agricultores dos assentamentos de Reforma Agrária do DF, não compartilhava a mesma necessidade de certificação externa e de multiplicar pontos de venda. 
No início, os produtores do Assentamento Colônia 1 e de Brazlândia, antes de existir a certificação participativa, não eram certificados. Produziam segundo os princípios da agroecologia e vendiam os produtos na base da confiança e da reputação, na Universidade de Brasília, em frente à EMATER-DF ou ao Ministério de Meio Ambiente ou até embaixo do prédio do Sindicato Rural. Eles saíram da AGE em 2009 e em 2012, porque não aceitavam ter a obrigação de passar mais tempo, duas vezes por semana e, sobretudo os sábados, para vender muitos produtos e até conservas, uvas e cogumelos dos produtores empresariais, como da Fazenda Malunga, entre outros, quando eles traziam poucos produtos próprios.

\section{O grupo de interesse do setor público}

Os membros desse grupo são funcionários públicos das seguintes instituições: Universidade de Brasília, Embrapa, MAPA, MDA e EMATER-DF (ver tabela1). No caso da Universidade de Brasília, existem dois núcleos de agroecologia que associam vários estudantes aos professores. Seus membros apresentam, todos, um nível de educação superior, experiência profissional na agricultura (muitos são engenheiros agrônomos) e, portanto, são dotados de vários recursos políticos individuais e coletivos. $O$ Centro Vocacional Tecnológico em Agroecologia e Agricultura Orgânica da UnB (CVT-UnB), embora não se inscreva na categoria dos Núcleos de Estudos da Agroecologia (NEAs), existe desde 2014. Focaliza sua ação na produção orgânica, bem como na formação de produtores e extensionistas para esse setor. Tem parceria com EMATER, EMBRAPA e IFB, desenvolve atividades experimentais na Fazenda Água Limpa e em propriedades nas regiões de Brazlândia, Planaltina e São Sebastião, denominadas "vitrines agroecológicas". Pelo seu perfil, são frequentemente envolvidos em ações de capacitação, pesquisa ou extensão, mas também, de assessoria política, formação de agricultores, técnicos e para formulação de recomendações em matéria de instrumentos de políticas públicas de agroecologia, produção orgânica, certificação, comercialização, compras públicas, crédito e extensão rural agroecológica.

Por outro lado, em função dessa expertise, também são chamados a ocupar cargos de confiança em órgãos da administração pública no setor da agricultura a nível distrital ou federal, acumulando experiência, capital social, típicos deste tipo de ator multi-posicionado (MASSARDIER, 2008). Tais atores apoiaram tanto as iniciativas a favor da estruturação da produção orgânica (CPORG, certificação inclusive participativa, Mercado dos orgânicos) como da agroecologia (feiras agroecológicas, NEAs e seminários e eventos em Brasília).

A EMATER-DF, a CEASA-DF e, em menor grau a UnB e a Embrapa, têm apoiado a construção do Mercado Orgânico, mas também, a implementação da feira da agricultura familiar e da agroecologia no espaço da CEASA. Uma característica central desse grupo do setor público é o fato de que vários dos indivíduos que o compõem defenderem a agroecologia e a produção orgânica no seio de instituições federais e distritais. Mas eles têm alcançado um destaque importante nesse sentido, além da escala do $\mathrm{DF}$, por três motivos fundamentais. Primeiro, alguns trabalham em ministérios ou instituições federais (MAPA, MDA, EMBRAPA, UnB) e, ao mesmo tempo, assumem funções e liderança no movimento social da agroecologia (ABA e ANA). Isso significa que, antes de promover a PDAPO no DF, eles tinham experiência adquirida na elaboração da política de produção orgânica e logo da própria PNAPO.

Em segundo lugar, os membros da academia mantêm laços com os produtores agroecológicos familiares dos assentamentos de reforma agrária do DF, mediante cursos e reuniões, visitas e unidades demonstrativas. Terceiro, em termos de preparação de instrumentos de política pública, além da sua trajetória militante e dos seus recursos (capital social, conhecimentos temáticos, capital educativo) eles conseguem certa eficiência graças à sua situação de multiposição entre setor público, movimentos sociais e produtores. Eles adotaram uma estratégia pragmática de considerar a produção orgânica como uma possível etapa na transição para a agroecologia. Por isso, também sempre apoiaram instrumentos a favor da produção orgânica. Esse comportamento faz com que esse grupo seja a favor dos dois sistemas. Esse grupo de interesse associa membros da academia e funcionários da EMATER-DF, os quais têm um perfil mais técnico e pragmático, pela sua função de assistência técnica a todos os tipos de agricultores do DF (do empresário médio produtor de soja com plantio direto, até os assentados agroecológicos, passando por agricultores familiares, pecuaristas, e pequenos empresários 
dos orgânicos). Os extensionistas da EMATER-DF, que estão em contato permanente com os agricultores, seguem o perfil de "burocratas de nível de rua" (LIPSKY, 1980). Eles têm uma visão mais técnica da agroecologia (conservação do solo, luta biológica, uso de bio-insumos, etc.). Este é, também, o caso dos funcionários da CEASA-DF.

No outro espectro, na academia, docentes e estudantes membros dos NEAs, têm um perfil mais militante e ideológico. Defendem a proposta de Altieri (1995) de uma agroecologia política, na medida em que promove antes de tudo, um sistema agroalimentar alternativo ao domínio do modelo produtivista convencional do agronegócio (SABOURIN et al., 2018, p.2). São extremamente ativos, tanto na organização de eventos quanto no acompanhamento de ações nos assentamentos de reforma agrária do DF. Os líderes desse grupo correspondem praticamente ao núcleo fundador da ABRAA, multiposicionados, bem informados e detentores de um alto nível de recursos políticos, em particular de uma bagagem técnico-científica e de uma rede de relações pessoais como institucionais. Aproveitando-se, também, da experiência acumulada numa trajetória militante e profissional, foram determinantes para a criação da PDAPO-DF.

Uma rede de ação pública para agroecologia e produção orgânica

O conjunto desses três grupos de interesse configura uma coalizão ampla de política pública de agroecologia e produção orgânica na escala do DF, cujos principais elementos constitutivos e características, de acordo com Sabatier e Jenkins (1993): membros componentes, crenças e valores, recursos políticos, arenas e espaços específicos, assim como modalidade de interação, estão resumidos na tabela 1 a seguir. O conjunto das interações e articulações dessa rede de ação pública é representado na figura 2 . No entanto, a sub-coalizão da agroecologia tem desenvolvido, na última década, uma forma particular de articulação em rede. A ABRAA é um dos resultados desse trabalho de abertura de variadas frentes e de ocupação de espaços em prol da agroecologia, para além do mercado, da produção e da legislação.

Tabela 1. Elementos constitutivos nos três grupos de interesse que constituem a grande coalizão da agroecologia e produção orgânica no DF

\begin{tabular}{|c|c|c|c|c|}
\hline $\begin{array}{l}\text { Grupo } \\
\text { Interesse }\end{array}$ & de & Grupo da produção Orgânica & Grupo do Setor Público & Grupo da Agroecologia \\
\hline \multirow{13}{*}{\multicolumn{2}{|c|}{$\begin{array}{l}\text { Principais } \\
\text { membros }\end{array}$}} & $\begin{array}{l}\text { Associação dos Agrônomos do } \\
\text { DF, AGE }\end{array}$ & $\begin{array}{l}\text { Universidade de Brasília: FAV, } \\
\text { CDS, FUP-NEPEAS, NEA }\end{array}$ & $\begin{array}{l}\text { AGE, ABRAA } \\
\text { Assent. Colonia 1. P Bernardo }\end{array}$ \\
\hline & & CPORG-DF & & Aprospera/ S Bartolomeu \\
\hline & & Sindicato dos Orgânicos & Instituto Federal Agrícola DF & Ass. Ass. Chapadinha \\
\hline & & Fundação M. Okada & & Ass. Prod. Agroecológicos Lago Oeste \\
\hline & & Ecocert Brasil & Embrapa (Hortaliças, Cerrado & Ass. Prod. Agroecológicos São Sebastião \\
\hline & & SEBRAE-DF e INDEC & e Cenargen) & Ass. dos Prod Rurais do INCRA 09 \\
\hline & & CEASA-DF & & Ass dos Prod Rurais e Agric Fam do \\
\hline & & CONTAG-ARCO-TAE & MAPA - Coord AE e PO & INCRA IX \\
\hline & & CVT-UnB & & Ass dos Prod do P.A. Contagem \\
\hline & & $\begin{array}{l}\text { Coope Mercado Orgânico } \\
\text { Agro-Orgânica }\end{array}$ & MDA-SDT & $\begin{array}{l}\text { Ass do Grupo de Mulheres Prod do } \\
\text { Assent Contagem }\end{array}$ \\
\hline & & $\begin{array}{l}\text { Ass Mista dos A F Orgânicos e } \\
\text { Produtores Rurais do DF Ass dos }\end{array}$ & EMATER-DF & $\begin{array}{l}\text { Ass dos Prod Rurais de Alexandre } \\
\text { Gusmão }\end{array}$ \\
\hline & & Prod de Hortigranjeiros do DF & CAO & Asso dos Prod Fam Agroecológicos DF e \\
\hline & & $\begin{array}{l}\text { Empresas: Malunga, Sitio } \\
\text { Corujinha, Kapra, Desifrut, D'ro, } \\
\text { Videiras do lago, MamaGé, Cogu, } \\
\text { Hatidori }\end{array}$ & CEASA-DF & $\begin{array}{l}\text { entorno } \\
\text { Ass dos Trab Rurais do Assent Três } \\
\text { Conquistas } \\
\text { NEPAS-FUP, NEA -UnB }\end{array}$ \\
\hline Crenças & & $\begin{array}{l}\text { Visão empresarial e comercial; } \\
\text { alimentação saudável }\end{array}$ & $\begin{array}{l}\text { Visão pragmática de serviço } \\
\text { aos produtores e } \\
\text { consumidores }\end{array}$ & $\begin{array}{l}\text { Visão mais radical na transformação dos } \\
\text { sistemas agroalimentares }\end{array}$ \\
\hline Recursos & & $\begin{array}{l}\text { Políticos, capital financeiro, } \\
\text { empresariais }\end{array}$ & $\begin{array}{l}\text { Poder federal ou distrital, } \\
\text { capital social e educativo }\end{array}$ & $\begin{array}{l}\text { Capital social e educativo, acesso a redes } \\
\text { de Mov. Sociais }\end{array}$ \\
\hline $\begin{array}{l}\text { Arenas } \\
\text { espaços }\end{array}$ & e & $\begin{array}{l}\text { A L DF, CEASA, FAPE-DF- } \\
\text { Sindiorganicos, SEAGRI }\end{array}$ & $\begin{array}{l}\text { Administração distrital e } \\
\text { federal e escritórios regionais } \\
\text { da Emater DF }\end{array}$ & Seminários e eventos, academia, AL DF \\
\hline Interações & & Mediante AGE e algumas feiras & $\begin{array}{l}\text { Emater DF e UnB são pontes, } \\
\text { Embrapa e MAPA }\end{array}$ & AGE e UnB agem como pontes \\
\hline
\end{tabular}


Instituições que são comuns às duas coalizões da produção orgânica e da agroecologia e/ou que realizam a ponte entre seus respetivos membros.

Os membros desta rede entendem que é possível haver uma convivência entre promotores da Agroecologia e da Produção Orgânica. Um fator que tem contribuído para a sinergia observada entre os atores da ABRAA é o fato destes já se conhecerem antes da formação da rede e de compartilhar o mesmo mundo do serviço público, da pesquisa e do ensino. Todos são pesquisadores, professores, agentes de assistência técnica rural ou estudantes.

Figura 2. Esquema da rede de ação pública da agroecologia e produção orgânica no DF

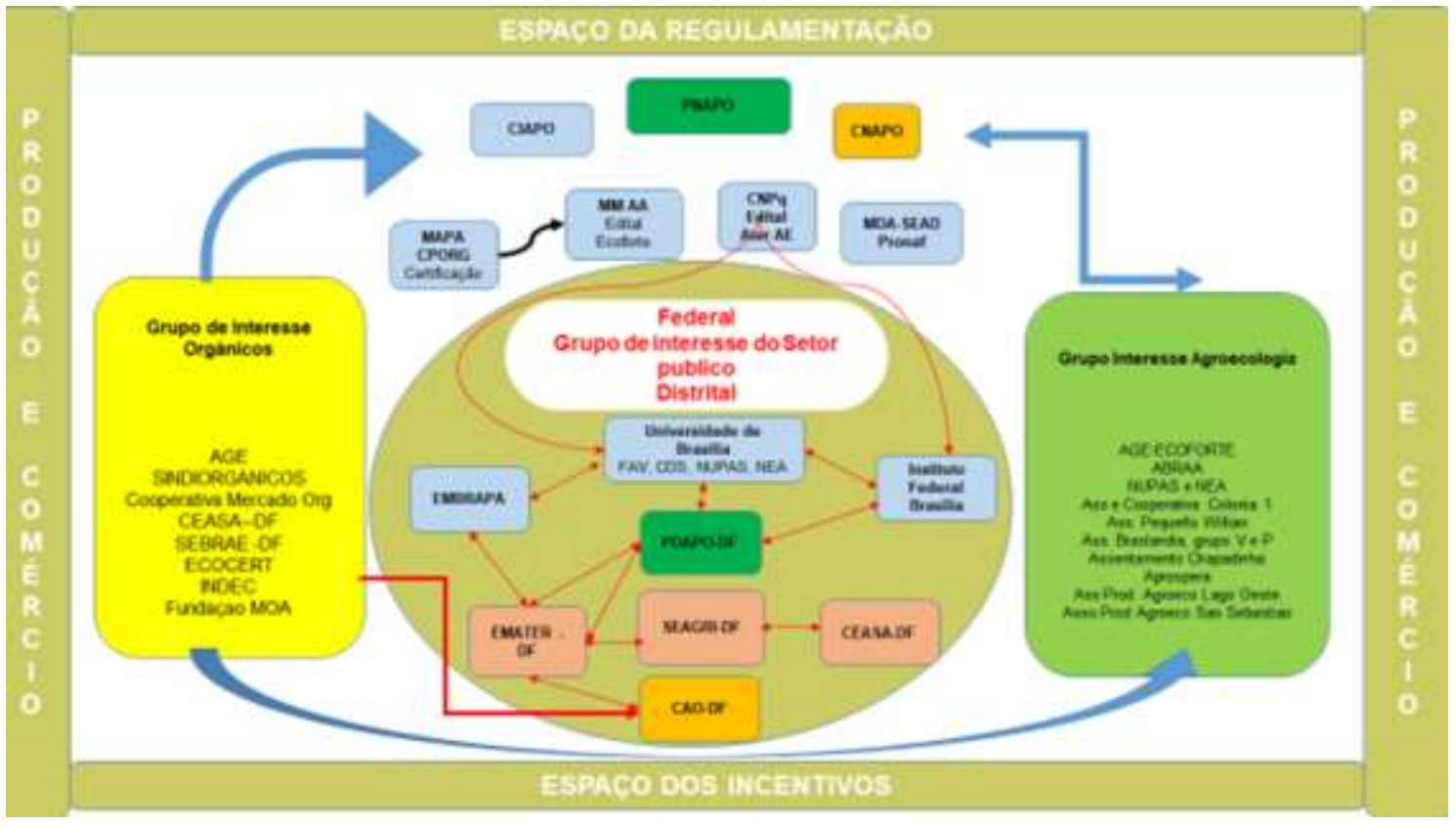

Marsh e Rhodes (1992) distinguem cinco tipos de redes de ação pública: i) a rede temática, ii) a rede de produtores (de ideias), iii) a rede intergovernamental, iv) a rede profissional (ou setorial); e v) a comunidade de políticas públicas. Estes autores propõem enfatizar as redes temáticas e a comunidade de política pública. No caso da PDAPO-DF, as redes temáticas correspondem aos grupos de interesse dos orgânicos e da agroecologia, enquanto a rede intergovernamental corresponde às instituições do setor público federal e distrital, já a comunidade de política pública, corresponde ao conjunto dos atores mobilizados na rede de ação pública da agroecologia e produção orgânica.

A identificação de atores multi-posicionados nos indica relações dinâmicas entre as sub-redes temáticas ou grupos de interesses e permite evidenciar o papel de intermediário ou de mediador, que assumem entidades como a AGE, a EMATER-DF ou a UnB. De fato, as redes de ação pública produzem sentido e conhecimentos, portanto, se constituem a partir de uma matriz cognitiva comum. Isto é particularmente evidente no caso da sub-rede da agroecologia e da preocupação dos seus membros em manter uma identidade e uma dinâmica de gestão do conhecimento agroecológico. Desta forma, a coalizão da agroecologia se identifica como uma comunidade epistêmica.

Le Galès e Tatcher (1995) associam a rede de ação pública a processos de governança. Eles definem a governança como um "processo de coordenação de atores, de grupos sociais, de instituições para atingir metas próprias, discutidas e definidas coletivamente em ambientes fragmentados e incertos". Essa definição traduz bem a fragmentação e a incerteza que envolvem a realidade como o futuro das políticas para agroecologia no Brasil e no DF. 
Instituições e resultados: governança e instrumentos da PDAPO-DF

As instituições no sentido de Lascoumes e Le Gales (2012) são os procedimentos e dispositivos que governam as interações entre os atores da ação pública. No caso da PDAPO-DF, tendo a CPORG perdido importância, é a CAO que constitui o novo espaço de governança entre os representantes dos três grupos de interesse.

A execução da PDAPO-DF é confiada à SEAGRI, atuando, principalmente, através da EMATERDF. Para a orientação, acompanhamento e avaliação da PDAPO foi criada a Câmara Setorial de Agroecologia e Produção Orgânica do DF, a CAO.

A CAO foi criada pelo Decreto no $38.618 / 2017$ e passa a ser a instância de gestão da PDAPODF. Ela é um órgão consultivo do Governo do Distrito Federal, vinculado à SEAGRI-DF, com o objetivo de debater e acompanhar ações e apresentar proposições relacionadas ao desenvolvimento da agroecologia e da produção orgânica no Distrito Federal. Compete à CAO, junto ao PDAPO-DF: 1) a proposição das diretrizes, dos objetivos, dos instrumentos e das prioridades da PDAPO; 2) a interação das instâncias governamentais e não governamentais relacionadas à agroecologia e produção orgânica; 3) o acompanhamento da execução das ações da PDAPO-DF; 4) a coordenação, a mobilização e o monitoramento das ações e dos processos que contribuam para o cumprimento da PDAPO-DF; 5) os projetos, as ações e a previsão dos recursos financeiros; 6) as responsabilidades e os indicadores de monitoramento e avaliação; e 7) as ações de fomento à agroecologia e a produção orgânica do Distrito Federal.

A CAO é composta de forma paritária por sete representantes titulares e suplentes do governo: SEAGRI-DF; Secretaria de Estado do Meio Ambiente do DF, Secretaria de Trabalho, Desenvolvimento Social, Mulheres, Igualdade Racial e Direitos Humanos do DF, EMATER/DF, MAPA, EMBRAPA e, também, por sete representantes da agroecologia e da produção orgânica da sociedade civil: Federação dos Trabalhadores na Agricultura Familiar (FETRAF-DF), SINDIORGÂNICO, COOPERORG, AGRORGÂNICA, SEBRAE/DF; IFB; Cooperativa de Trabalho e Desenvolvimento da Agricultura Camponesa (CODESTAC). A CAO já tem regimento interno aprovado e realizou uma oficina no final do ano 2018 para a preparação do Plano Distrital de Agroecologia e Produção Orgânica (PLADAPO), a ser elaborado em 2019. Até fevereiro de 2019, os rumos da PDAPO-DF não parecem ser alterados com a posse do novo governo. No entanto, a CAO foi desestruturada: representantes de entidades com cargo de livre exoneração (da SEAGRI, EMATER-DF e das organizações de produtores) saíram no fim do governo Rollemberg.

Quanto aos instrumentos que constituem, ao mesmo tempo, o resultado e a operacionalização do processo de ação pública, no caso da PDAPO-DF, eles incorporam os programas preexistentes dentro da SEAGRI e EMATER-DF, antes de serem completados por novas ferramentas ou propostas no marco do plano em elaboração.

A EMATER-DF identifica três fontes de financiamento: i) os instrumentos da política federal: ATER agroecologia (capacitação, campos demonstrativos, visitas dos técnicos), contratos de Assistência técnica para DF e entorno; linhas de crédito federal e distrital, Programa Prospera/Fungep; Pronaf Agroecologia e compras públicas de alimentos (PAA e PNAE); ii) recursos da PDAPO-DF: Programa de Aquisição da Produção da Agricultura (PAPA-DF) com R\$ 2,5 milhões para agroecologia e produção orgânica, incentivos a pesquisa/ater com redes de financiamento de credito; iii) emendas parlamentares: em 2018, por intermédio de um deputado federal foi conseguida uma emenda de $\mathrm{R} \$$ $600.000,00$ para apoio a 630 agricultores familiares da reforma agrária receberem programa de SAF de produção de morangos, irrigação, Transição Agroecológica (TAE) e comercialização em TAE.

A EMATER-DF operacionaliza os seguintes programas de crédito rural: FDR-DF, PRONAF, Fundo Constitucional do Centro-Oeste (FCO) e PROSPERA. O Fundo Programa de Microcrédito Produtivo Orientado (PROSPERA), criado pela Lei Complementar № 005/1995 (FUNSOL) destina crédito para agricultores familiares e assentados da reforma agrária.

As linhas Agroecologia e Eco, do PRONAF e do DF, são pouco acessadas por falta de divulgação mais do que por resistência do banco (embora os bancos prefiram os créditos para produtores 
patronais com juros mais elevados) como os do FCO. Por isso a capacitação dos técnicos do banco sempre é necessária porque, quem executa crédito rural nos bancos tem pouco conhecimento sobre questões agrícolas, sobretudo no que se refere à agroecologia e à produção orgânica. De acordo com os responsáveis da EMATER-DF, o PRONAF deixou de ser uma linha "a fundo perdido" ou com juros muito baixos. O seu acesso pelos agricultores familiares do DF é dificultado pela falta de regularização fundiária e de acesso à Declaração de Aptidão ao Pronaf (DAP). Segundo a EMATER-DF, muitos assentados da reforma agrária não têm perfil ou tradição para acessar crédito com sucesso. Porém, pelo que observamos, os agricultores que produzem em sistemas agroecológicos e comercializam nas feiras, na CEASA e nos restaurantes, mostram capacidades de gestão que deveriam lhes garantir o acesso ao crédito. Muitos fazendeiros da região não chegam aos mesmos níveis de produtividade e qualidade destes produtores. No DF, segundo a então coordenadora de agroecologia da EMATER, só se tem conhecimento de um contrato de Pronaf Agroecologia.

\section{Instrumentos que dialogam com a PNAPO ou com efeitos mais relevantes}

A PDAPO-DF foi normatizada em novembro de 2017 pela SEAGRI, e a EMATER-DF a executa. Para a EMATER-DF, existe uma boa articulação entre a PNAPO (se ela for mantida) e a PDAPO-DF. Primeiro, é preciso articular orçamentos entre a programação federal (4 anos) e a do DF (anual). Mas já são implementadas atividades de capacitação e fomento com previsão de criação de centros de referência para agroecologia e produção orgânica no DF com apoio da PNAPO. Cinco instrumentos são, principalmente, objeto de interações e coordenações entre a PNAPO e a PDAPO-DF: o crédito, como já indicado, a ATER, a comercialização, a certificação e o apoio a organização de redes.

No DF o principal instrumento para agroecologia que dialoga com a PNAPO é a ATER agroecológica, associada às evoluções da PNATER, desde 2004, e a criação da PNAPO. Segundo R. Garcia a então coordenadora de agroecologia da EMATER-DF, todos os escritórios locais teriam, agora, competência em agroecologia e produção orgânica. De maneira geral, a ATER se divide entre apoio técnico à produção e apoio à certificação. A maioria do trabalho do extensionista para agroecologia e produção orgânica constitui em sensibilização e capacitação, não é só dia de campo. $O$ apoio à produção passa por visitas sistemáticas, unidades demonstrativas e, teoricamente, a elaboração de projetos de crédito. Em 2017, 1.714 agricultores e agricultoras receberam ações de ATER para o desenvolvimento da agroecologia e agricultura orgânica. Essas ações culminaram no aumento da produção certificada, fazendo com que a EMATER-DF negociasse a sua inserção mediante programas de compras públicas de alimentos orgânicos junto ao programa distrital (PAPA-DF) ou aos programas federais (Programa de Aquisição de Alimentos - PAA e Programa Nacional de Alimentação Escolar PNAE). No total, foram 134 produtores familiares beneficiados com esses programas de governo. Com a ampliação das formas de certificação para produção orgânica e agroecologia, foi possível aplicar preços melhores (15 a 30\% superiores) para produtos agroecológicos e orgânicos, nas compras públicas a agricultura familiar que têm estimulado a produção orgânica e agroecologia.

O Governo do DF tem apoiado contratos de compras públicas de alimentos com agricultores da reforma agrária. Por exemplo, o programa PAPA-DF mobiliza $\mathrm{R} \$ 13$ milhões/ano, dos quais $10 \%$ para a produção agroecológica. Uma linha do PAPA-DF chama-se "Cesta verde", para produção orgânica, e representou, em 2017, um total de $\mathrm{R} \$ 1.800 .000$ para 30 a 40 Agricultores familiares certificados. Eram 50 produtores certificados em 2010, 200 em 2015, 272 em 2018. A criação de Organizações Participativas de Avaliação da Conformidade (OPAC) no marco da AGE e do Sindiorgânicos ofereceu alternativas a certificação por auditoria externa via Ecocert ou MOA. OPAC e Organizações de Controle Social (OCS) permitiram uma adesão maior de produtores agroecológicos que não podiam financiar uma certificação por auditoria externa, sobretudo nas áreas de assentamentos: Paranoá, São Sebastiao, Brazlândia, Planaltina.

Os responsáveis da EMATER reconhecem que a agroecologia no DF, concretamente, tem progredido muito pela influência dos movimentos sociais de luta pela terra. A produção agroecológica familiar do DF está, na sua grande maioria, restrita aos assentamentos. Não foi por acaso que a CNAPO, 
para o PLANAPO II exigiu mais esforço de reforma agrária ou fundiária (mais acesso à terra) para promover a agroecologia. No DF, o morango orgânico é, tipicamente, um produto dos assentamentos.

O Ecoforte representou a principal inovação da PNAPO. Trata-se de um programa de fortalecimento institucional e capacitação para redes de gestão de conhecimento agroecológico descentralizadas. O programa contava, em 2014, com um orçamento de $\mathrm{R} \$ 34,6$ milhões de investimento social da Fundação Banco do Brasil e de Fundo Amazônia, gerido pelo Banco Nacional do Desenvolvimento Econômico e Social (BNDES) e, em 2017, com R\$ 25 milhões para o último edital. Na região Centro-Oeste, a AGE é responsável pela execução da Rede Agroecológica Planalto Central, uma das 28 redes habilitadas pelo edital Ecoforte Redes, voltado a projetos de produção agroecológica e agroextrativista sustentável. Esse projeto envolve diretamente 3.216 produtores do DF e mais três municípios: Cidade Ocidental e Padre Bernardo, em Goiás, e Unaí, em Minas Gerais. Os produtores passam por capacitação, compartilham equipamentos e veículos adquiridos no projeto, trocam experiências e juntam forças na logística de comercialização e distribuição dos produtos em feiras livres. A EMATER-DF, a UnB e a Embrapa participam do apoio dentro dessa rede.

\section{Conclusões}

A PDAPO-DF tem como objetivo ampliar o enfoque agroecológico nas propostas de desenvolvimento rural do Distrito Federal, contemplando novas bases metodológicas, técnicas e científicas. Visa promover estratégias e ações objetivas para iniciação e progresso pelos caminhos da transição agroecológica e contribuir para o aumento da produção de alimentos saudáveis pela construção de sistemas de base ecológica. Trata-se de uma política muito recente, com implementação a partir de 2019, portanto, é muito cedo para avaliar resultados ou impactos. No entanto, essa política tem um longo histórico e foi precedida pela aplicação de outros instrumentos distritais ou federais, que permitem analisar as bases de interação entre o nível distrital e o nível federal, hoje, através da PNAPO.

Em termos de ensinamentos da análise da construção da PDAPO-DF, podemos reter três elementos centrais: primeiro, a reivindicação e promoção dessa política distrital de agroecologia e produção orgânica é o fruto dos esforços de uma coalizão criada em torno de pioneiros da agricultura alternativa desde os anos 1980. Esses pioneiros têm todas as características de um núcleo próximo e solidário de elites programáticas que teve a capacidade de atuar e mostrar influência nas mais altas esferas da política, dos ministérios, da administração distrital, da pesquisa federal e da UnB, assim como entre os produtores. Os produtores do setor dos orgânicos, na sua maioria pequenos e médios empresários, se caracterizam pela sua capacidade empresarial, atuando como verdadeiros empreendedores de política pública, principalmente na estruturação da comercialização (mercados, cooperativa) e na certificação (inclusive participativa) dos orgânicos.

A articulação da agroecologia reúne os intelectuais orgânicos (academia e alta administração) e poucos agricultores agroecológicos dos assentamentos de reforma agraria. Ainda não possui as características de um movimento social da agroecologia integrando produtores e consumidores. A ABRAA ficou mais centrada no apoio a gestão do conhecimento agroecológico e na promoção de seminários. A reunião de entidades dos três grupos de interesse na Rede de Agroecologia do Planalto Central, mais centrada nessa função de compartilhamento do conhecimento, poderia constituir uma base regional indo além da especificidade do DF, dos seus consumidores e produtores. No entanto a não renovação de chamadas do programa Ecoforte, pode comprometer essa iniciativa atualmente fragilizada. O conjunto destes três grupos de interesse se caracteriza, no entanto, como uma potencial rede de ação pública a favor da agroecologia e da produção orgânica no DF, que tem conseguido, em torno de um grupo de uma dezena de indivíduos centrais e multiposicionados, manter uma pressão para a elaboração de instrumentos de política pública que culminaram em 2017 na promulgação da PDAPO-DF.

Em segundo lugar, cada sub-coalizão (agroecologia e produção orgânica), tem mais aproximação com um determinado perfil de produtores: $O$ principal público do apoio da EMATER, assim 
como dos dois NEAs da UnB, é a produção agroecológica e orgânica em assentamentos. Por outro lado, a produção orgânica, que tem se fortalecido em torno dos restaurantes e do Mercado Orgânico na CEASA, envolve pequenos e médios empresários, aposentados do serviço público e profissões liberais detentores de terras ou de chácaras.

Em terceiro lugar, a proposta da PDAPO integrou uma visão ampla da agroecologia e da produção orgânica: ações de combate à pobreza, inclusão social e produtiva, promoção da segurança e soberania alimentar, da equidade, justiça e cidadania no campo, também são alvos estratégicos dessa política. No entanto, até hoje, o programa de Agroecologia e Produção Orgânica da EMATER-DF tem sido mais centrado na tecnologia de produção. De fato, na PDAPO-DF estão incluídas diversas e novas ações mais sociais e amplas, como a capacitação e organização social dos agricultores, visando a transição agroecológica, o acesso aos mercados diferenciados, mas essas atividades precisam encontrar recursos e estruturas. Isto deveria ser o objeto da realização do Plano Distrital de Agroecologia e Produção Orgânica do DF no marco da CAO. Ainda é prematuro analisar resultados e efeitos. No entanto, nos trabalhos de campo, elementos significativos têm sido observados como a menor dependência externa de insumos caros e não renováveis, as melhorias sociais e econômicas, a inserção das mulheres na produção ecológica e o acesso a mercados diferenciados, que é bem característica do DF. Se a EMATER-DF dispõe de extensionistas capacitados em agroecologia e de um programa de compras públicas (PAPA-DF), a maioria das ações importantes de apoio estrutural dependem de financiamentos federais. Os desafios residem, essencialmente, na consolidação das organizações tanto de produtores agroecológicos quanto dos consumidores.

\section{Agradecimentos}

Esse artigo é resultado de uma pesquisa realizada no marco do contrato de professor visitante externo de Eric Sabourin no Centro de Desenvolvimento Sustentável da Universidade de Brasília (UnB) e do mestrado de Luiz Raimundo Tadeu na Silva no Programa de Pós-Graduação Meio Ambiente e Desenvolvimento Rural (MADER) da UnB, Faculdade de Planaltina. Contou com o apoio do CIRAD (Centre de coopération internationale en recherche agronomique pour le développement - França) através da Rede Políticas Públicas e Desenvolvimento Rural na América Latina (Rede PP-AL). Os autores agradecem o apoio dessas instituições.

\section{Referências}

ALTIERI, M. A. Agroecology: The Science of Sustainable Agriculture. CRC Press, 1995.

DISTRITO FEDERAL. Decreto 38618 de 16/11/2017. Regulamenta a Lei no 5.801, de 10 de janeiro de 2017, Política Distrital de Agroecologia e Produção Orgânica - PDAPO.

DYE T. R. Understanding public policy, Englewood Cliffs, N.J: Prentice-Hall, 1984.

GENIEYS, W. L'émergence d'élite(s) programmatique(s) face à la mutation de l'État français, Barcelona Institut de Ciències Polítiques i Socials, CNRS, WP n. 261, 2007.

GUENEAU, S. et al.; Construção de políticas públicas de agroecologia nos Estados Federados do Brasil Revista Brasileira de Agroecologia (esse número)

GLIESSMAN, S. Agroecology: The Ecology of Sustainable Food Systems. CRC Press, 2014.

KINGDON, J. Agendas, alternatives and public policies. Boston, MA: Little, Brown, 1984.

LAGROYE J. ;et al. Sociologie politique. Paris : Dalloz-Sirey, 2006.

LANDEL, $P$. Sociogenèse d'un projet de développement rural territorialisé - Le cas du Marché Organique à Brasilia, dans le Territoire Aguas Emendadas au Brésil. Lyon : Université Lumière Lyon II, 2009. 100 p. Dissertação (Master 1 -Sciences Politiques).

LASCOUMES P.; LE GALES P. Sociologia da ação pública, Maceió: Edufal, 2012.

LE GALES, P.; THATCHER N. Les réseaux de politique publique. Débat autour des policy networks Paris, Harmattan, 1995, DOI : https://doi.org/10.3406/polix.1997.1660.

LIPSKY, M. Street-level Bureaucracy: dilemmas of the individual in public services. New York: Russell Sage Foundation, 1980. 
MARSH, D.; RHODES, R.A.W. Policy networks in British government. Oxford /New York: Clarendon Press Oxford University Press, 1992.

MASSARDIER, G. Politiques et actions publiques, Paris: Armand Colin. 2008.

PAL, L. Public Policy Analysis: An Introduction. Toronto: Nelson, 1992.

RHODES, R. "Policy network analysis", in MORAN, M.; REIN, M.; GOODIN, R. E. (Eds), The Oxford handbook of public policy, Oxford: University Press, 2008, p. 425-443.

SABATIER, P.; JENKINS-SMITH, H. (Eds.) Policy Change and Learning: An Advocacy Coalition Approach. Boulder, CO: Westview Press, 1993.

SABOURIN E.; et al. Public policies to support agroecology in Latin America and the Caribbean, Montpellier: CIRAD, Perspective 45, 2018.. https://doi.org/10.19182/agritrop/00020.

SCHMITT, C.; et al. La experiencia brasileña de construcción de políticas públicas a favor de la agroecología, in Sabourin, E.; Patrouilleau, M.M.; Le Coq, J.F.; Vasquez, L.L.; Niederle P. (Org) Políticas públicas a favor de la agroecología en América Latina y El Caribe, Porto Alegre: Criação Humana/Red PP-AL, 2017, p. 73-122.

SIMEON R. Studying Public Policy Canadian journal of political science, v. 9, n4, 1976, p. 548-580.

TADEU DA SILVA, L. A construção da Agroecologia no Distrito Federal através de uma rede de ação pública. Dissertação de Mestrado. Programa de Pós-Graduação em Meio Ambiente e Desenvolvimento Rural (PPG/MADER). Universidade de Brasília, 2019. 